\title{
Inflammatory bowel disease and ankylosing spondylitis associated with cutaneous vasculitis, glomerulonephritis, and circulating IgA immune complexes
}

André J Peeters, A Warmold L van den Wall Bake, Mohamed R Daha, Ferdinand C Breedveld

\begin{abstract}
Two patients both with inflammatory bowel disease (IBD) and ankylosing spondylitis (AS) developed leucocytoclastic vasculitis of the skin and nephropathy. Immunofluorescence studies showed that there was perivascular deposition of immunoglobulin $A$ in the skin biopsy specimens of both patients and in the renal mesangium of one patient. Serum samples of the two patients contained IgA immune complexes. The absence of previous reports on such a combination of symptoms in IBD or AS suggests that these patients may have a disease entity which is distinct from uncomplicated IBD or AS, and which may combine the immunopathological features of both underlying disorders.
\end{abstract}

The coexistence of inflammatory bowel disease (IBD) and ankylosing spondylitis (AS) is well known. Four per cent of patients with AS have IBD; conversely $6 \%$ (range $1-25$ ) of patients with IBD have AS. ${ }^{12}$ It is thought that IBD and AS result from immunological dysfunction, although the exact pathogenesis is not known. Increased concentrations of serum $\operatorname{IgA}$ and $\operatorname{IgA}$ immune complexes have been reported in both diseases. ${ }^{3-6}$ IgA nephropathy, a disease thought to result from renal deposition of circulating IgA immune complexes, ${ }^{78}$ has been mentioned as part of the disease spectrum of AS by many authors ${ }^{9-11}$ and has been described in association with IBD in three patients. ${ }^{11}{ }^{12}$ Leucocytoclastic vasculitis with vessel wall deposition of IgA has not been previously reported in either of these diseases. We present data on two patients known to have had IBD and AS for many years who developed skin lesions and haematuria.

\section{Case reports}

CASE

A 16 year old boy presented with distal colitis and was treated with rectal steroids and oral sulphasalazine. A subtotal colectomy and ileostomy were performed three years later because of persistently active colitis. Histological examination of the resected colon showed extensive inflammation, but a classifying diagnosis could not be made. Five years later the rectum was resected because of persistent rectal blood loss due to proctitis.

Aged 25, he visited the rheumatology outpatient clinic because of lower back pain and early morning stiffness, both of which improved on exercise. Movement of the lumbar spine was restricted in three planes and radiography showed bilateral sacroiliitis. He was negative for the HLA-B27 antigen. An exercise programme was advised and non-steroidal anti-inflammatory drugs were prescribed.

By the age of 35 he was admitted because of painful skin lesions on both legs and fever. Blood pressure was $125 / 80 \mathrm{mmHg}$, pulse rate $84 /$ minute, and the temperature $37 \cdot 5^{\circ} \mathrm{C}$. On his left leg purpuric skin lesions were seen which were painful on palpation. Selected laboratory investigations showed an erythrocyte sedimentation rate (ESR) of $44 \mathrm{~mm} /$ first hour, a haemoglobin concentration of $132 \mathrm{~g} / \mathrm{l}$, and white cell count of $10.7 \times 10^{9} / 1$. Serum creatinine was $93 \mu \mathrm{mol} / \mathrm{l}$, total protein $84 \mathrm{~g} / \mathrm{l}$, albumin $51 \mathrm{~g} / 1$. Antinuclear antibody, latex agglutination, and Rose-Waaler tests yielded negative results. Cryoglobulins were not present and he was negative for hepatitis $B$ surface antigen (HBsAg). Further immunopathological data are presented in the table.

Urine analysis showed more than 20 red blood cells, two to five white cells, and some hyaline casts per high power field. Protein excretion was $0.6 \mathrm{~g} / 24$ hour. Urine culture showed no infection and an intravenous pyelogram was normal. A biopsy specimen of diseased skin showed leucocytoclastic vasculitis. Percutaneous renal biopsy was performed. Light microscopic examination showed no abnormalities. Dense mesangial deposits but with
Department of

Nephrology

University Hospital,

Leiden

A W L van den Wall Bake

M R Daha

Correspondence to

Dr A J Peeters,

University Hospital

Department of Rheumatology,

Building 1, C2-Q,

PO Box 9600

2300 RC Leiden,

The Netherlands.

Accepted for publication

21 September 1989
Immunopathological data of two patients with ankylosing spondylitis, inflammatory bowel disease, and nephritis

\begin{tabular}{lcc}
\hline Test (normal range) & Patient No I & Patient No 2 \\
\hline Serum IgA (0.9-3.5 g/l) & $4 \cdot 1$ & $6 \cdot 2$ \\
IgA inhibition assay $(<10 \mu g e q) *$ & 1070 & - \\
IgA polyethylene test $(<10 \mu g e q) *$ & 55 & 0 \\
Clq binding assay $(<10 \mu g e q)$ & 0 & 281 \\
Total haemolytic complement $(256-580 \mathrm{U} / \mathrm{l})$ & 786 & IgA, IgM, C3 \\
Cutaneous immunofluorescence & IgG, IgA, IgM, C3 & IgM, C3 \\
Renal immunofluorescence & IgA, IgM &
\end{tabular}

${ }^{*}$ Methods described in references 7 and 13 
normal epithelium and capillaries were found on electron microscopic examination. Bed rest was advised, treatment with ibuprofen was continued, and no further treatment was given. The skin lesion on his leg gradually healed. Serum creatinine remained normal and urine analysis intermittently showed red blood cells. Proteinuria did not increase.

\section{CASE 2}

A 30 year old man had proctitis; several years later the inflammation had affected the whole colon and ulcerative colitis was diagnosed. Intermittent treatment with rectal steroids and oral sulphasalazine controlled the colitis. At the age of $\mathbf{4 0}$ microscopic haematuria was found. An intravenous pyelogram was unremarkable. At the age of 44 the patient noted transient but recurrent erythematous maculae on both lower legs, some of which were tender. Subsequent ulcerations healed slowly. Three years later he was seen at the rheumatology outpatient clinic because of increasing lower back pain and stiffness of the vertebral spine (both improving on exercise) and pain in the left shoulder. Arthritis of the left sternoclavicular joint was found and movement of the lumbar spine was restricted in three planes. Radiological investigation showed bilateral sacroiliitis and syndesmophytes of the lumbar spine.

By the age of 50 he was admitted because of progressive ulcerative lesions measuring up to $4.5 \mathrm{~cm}$ in diameter on both lower legs. Blood pressure was $130 / 90 \mathrm{mmHg}$ and the pulse rate 76/minute. Apart from restricted movement of the lumbar spine and ulcers and scars on both lower legs, physical examination yielded normal results. His drug treatment on admission consisted of prednisone, sulphasalazine, and azapropazone. Selected laboratory investigations showed an ESR of $11 \mathrm{~mm} /$ hour, a haemoglobin concentration of $130 \mathrm{~g} / \mathrm{l}$, a white cell count of $8 \cdot 3 \times 10^{9} / 1$, a platelet count of $259 \times 10^{9} / 1$, serum creatinine concentration of $71 \mu \mathrm{mol} / \mathrm{l}$, total protein of $69 \mathrm{~g} / \mathrm{l}$, and albumin concentration of $49 \mathrm{~g} / \mathrm{l}$. Latex agglutination, Rose-Waaler test, and antinuclear antibody tests yielded negative results. Cryoglobulins were not found. Further immunopathological data are presented in the table. The HLA-B27 antigen was absent. Urinary sediment intermittently showed microscopic haematuria with more than 20 red blood cells per high power field. Protein excretion was $0.6 \mathrm{~g} / 24$ hour. Leucocytoclastic vasculitis was found in a skin biopsy specimen from the edge of an ulcerative lesion. Percutaneous renal biopsy was performed. Light microscopic examination showed no abnormalities. Electron microscopic examination showed a slight increase in size of the mesangial matrix, effacement of foot processes, and electron dense mesangial deposits. The skin ulcers were successfully treated with bed rest and a bland ointment.

\section{Discussion}

The rheumatology outpatient clinic of our hospital is regularly visited by about 300 patients with AS. Twelve of these patients are also known to have IBD. Review of published reports on extra-articular lesions in IBD and AS showed that there were more than 24 cases of IgA nephropathy in $\mathrm{AS}^{9-11}$ and three in $\mathrm{IBD}^{11}{ }^{12}$ : one of these patients had AS, ulcerative colitis, and IgA nephropathy. ${ }^{11}$ There were no reported descriptions of IBD or AS complicated by leucocytoclastic vasculitis with perivascular depositions of IgA. Skin lesions are not a feature of AS but are well known in IBD. Erythema nodosum, pyoderma gangrenosum, erythema multiforme, psoriasis, nodular necrobiosis, and epidermolysis bullosa may accompany IBD. ${ }^{14-17}$ Dermal vasculitis in IBD occurs as cutaneous polyarteritis nodosa and granulomatous vasculitis. ${ }^{18} 19$ Leucocytoclastic vasculitis is a rare complication of IBD. ${ }^{20-22}$ IgA deposits have not been reported in these patients.

Abnormalities of the humoral immune response have been described in both IBD and AS. Increased concentrations of serum immunoglobulins are commonly found in IBD. ${ }^{423}$ Several studies on patients with IBD reported the presence of circulating immune complexes containing predominantly IgG and, less often IgA and IgM. ${ }^{24}$ An association between the presence of circulating immune complexes and extra-articular manifestations in IBD, however, was not found. In AS active disease is related to high serum concentrations of $\operatorname{IgA} .^{3}$ Circulating IgA containing immune complexes were shown in a high percentage of patients with AS and might have been associated with the occurrence of haematuria. 52526

The two patients described in this report both had high concentrations of serum $\operatorname{IgA}$ and circulating IgA immune complexes. They both developed vascular lesions, and one patient also developed a renal lesion that might well be explained by the vascular deposition of IgA immune complexes. A diagnosis of HenochSchönlein purpura was not considered because the typical purpura, arthralgias, and gastrointestinal symptoms were not present. The presence of this unusual combination of signs in these two patier.ts suggests that the combination of two diseases, both associated with an abnormal regulation of the IgA immune response, had an essential role in pathogenesis.

1 Moll J M H. Inflammatory bowel disease. Clin Rheum Dis 1985; 11: 87-111.

2 Meuwissen S G M, Dekker-Saeys B J, Agenant D, Tytgat G N J. Ankylosing spondylitis and inflammatory bowel disease. Ann Rheum Dis 1978; 37: 30-2.

3 Franssen M J A M, van de Putte L B A, Gribnau F W J. IgA serum levels and disease activity in ankylosing spondylitis: a prospective study. Ann Rheum $D$ is $1985 ; 44$ : 766-71.

4 Smith A H, Macphee I W. A clinico-immunological study of ulcerative colitis and ulcerative proctitis. Gut 1971; 12: $20-6$.

5 Peeters A J, van den Wall Bake A W L, van Dalsen A D, Westedt M L. Relation of microscopic haematuria in ankylosing spondylitis to circulating IgA containing immune complexes. Ann Rheum Dis 1988; 47: 645-7.

6 Elmgreen J, Wiik A, Nielsen H, Nielsen O H. Demonstration of circulating immune complexes by the indirect leucocyte phagocytosis test in chronic inflammatory bowel disease. Acta Med Scand 1985; 218: 73-8.

7 Valentijn R M, Kauffmann R H, Brutel de la Rivière G, Daha $M R$, van Es L A. Presence of circulating macromolecular IgA in patients with hematuria due to primary IgA nephropathy. Am F Med 1983; 74: 375-81.

8 Czerkinsky C, Koopman W J, Jackson S, et al. Circulating immune complexes and immunoglobulin al. Circulating 
factor in patients with mesangial immunoglobulin A nephropathy. $\mathcal{F}$ Clin Invest 1986; 77: 1931-8.

y Bruneau C, Villiaumey J, Avouac B, et al. Seronegative spondyloarthropathies and IgA glomerulonephritis: a report of four cases and a review of the literature. Semin Arthritis Rheum 1986; 15: 179-84.

10 Chen A, Ho Y S, Tu Y C, Shieh S D, Hung H W, Chou C T. Immunoglobulin A nephropathy and ankylosing spondylitis. Immunoglobulin A nephrop

11 Dard S, Kenouch S, Méry J P, Baumelou A, Beaufils $H$ Baglin A. A new association: Ankylosing spondylitis (AS) Berger disease (BD). Kidney Int 1983; 24: 129.

12 Hubert D, Beaufils M, Meyrier A. Néphropathie glomérulaire à immunoglobulines $\mathrm{A}$ associée à une colite inflammatoire. A propos de deux observations. Presse Med 1984; 13: 1083-5.

13 Kauffmann R H, van Es L A, Daha M R. The specific detection of IgA in immune complexes. $\mathcal{F}$ Immunol Methods 1981; 40: 117-33.

14 Greenstein A J, Janowitz H D, Sachar D B. The extra-intestina complications of Crohn's disease and ulcerative colitis: a study of 700 patients. Medicine (Baltimore) 1976;55: 401-12.

15 Dantzi J T. Extraintestinal manifestations of idiopathic inflammatory bowel disease. Arch Intern Med 1988; 148: 297-302.

16 Whorwell P J, Haboubi N Y, Du Boulay C. Nodular necrobiosis in association with ulcerative colitis. Gut 1986; 27: 1517

17 Ray T L, Levine J B, Weiss W, Ward P A. Epidermolysis bullosa acquisita and intlammatory bowel disease. Am Acad Dermatol 1982; 6: 242-52.

18 Silverman $M \mathrm{H}$. Polyarteritis nodosa associated with ulcerative colitis. F R heumatol 1984; 11 : 377-9.

19 Burgdorf W Orkin M. Granulomatous perivasculitis in Crohn's disease. Arch Dermatol 1981; 117: 674-5.

20 Callen J P. Severe cutaneous vasculitis complicating ulcerative colitis. Arch Dermatol 1979; 115: 226-7.

21 Newton 1 A W ascultis and angio-oedema associated with inflammato bowel disease. Clin Exp Dermatol 1984, 9.618-23.

22 Barbado F J, Vazquez J J, Gil A, Ortiz Vazquez J. Vasculitis and ulcerative colitis. Gastroenterology 1980; 79: 417-8.

23 Rosekrans P C, Meijer C J, van der Wal A M, Cornelisse C J, Lindeman J. Immunoglobulin containing cells in inflam matory bowel disease of the colon: a morphometric and immunohistochemical study. Gut 1980; 21: 941-7.

24 Kemler B J, Alpert E. Inflammatory bowel disease associated circulating immune complexes. Gut 1980; 21: 195-201.

25 Deicher H, Ebringer A, Hildebrand S, Kemper A, Zeidler H. Circulating immune complexes in ankylosing spondylitis. Brf Rheumatol 1983; 22: 122-7.

26 Peeters A J, van den Wall Bake A W L, van Albada-Kuipers $\mathrm{GA}$, et al. IgA containing immune complexes and hematuria in ankylosing spondylitis. A prospective longitudinal study. f Rheumatol 1988; 15: 1662-7. 